\title{
Laparoscopic Surgery
}

National Cancer Institute

\section{Source}

National Cancer Institute. Laparoscopic Surgery. NCI Thesaurus. Code C15725.

Surgery done using a laparoscope. 